\title{
Is There (Will There Be) a Post-COVID-19 Chronic Cough?
}

\author{
Peter V. Dicpinigaitis ${ }^{1} \cdot$ Brendan J. Canning $^{2}$
}

Accepted: 2 November 2020 / Published online: 13 November 2020

(c) Springer Science+Business Media, LLC, part of Springer Nature 2020

Cough is among the most common symptoms associated with an acute viral upper respiratory tract infection (URI; common cold). In the vast majority of afflicted persons, acute cough (defined as cough of less than 3 weeks' duration) is transient and self-limited. However, in a subgroup of individuals recovering from a common cold syndrome, a dry, troublesome cough will persist as the sole residual symptom. Standard accepted terminology includes subacute cough as a cough lasting 3-8 weeks, and chronic cough greater than 8 weeks [1]. Indeed, clinicians treating patients with chronic cough will regularly obtain a history that the onset of chronic cough was temporally associated with an acute viral URI [2].

Various mechanisms have been proposed to explain viral URI-induced cough [3] as well as prolonged cough reflex hypersensitivity after acute URI [4]. Clinical studies incorporating capsaicin cough challenge, a common method of measuring cough reflex sensitivity, have demonstrated that the sensitivity of the cough reflex is enhanced during acute viral URI and remains so for a month or more beyond resolution of the viral syndrome [5-7].

When the COVID-19 pandemic struck in early 2020, the question arose as to whether infection with SARS-CoV-2 would generate a prolonged postviral cough, such as historically we have witnessed after other acute viral respiratory tract infections each year. Although we are still in relatively early days after the first wave of the pandemic hit North America and Europe, initial observational experience with post-COVID-19 patients supports the conclusion that there is not a high incidence of post-COVID-19 chronic cough and, when such a persistent cough does occur, it is not

Peter V. Dicpinigaitis

pdicpin@gmail.com

1 Albert Einstein College of Medicine and Montefiore Medical Center, 1825 Eastchester Road, Bronx, NY 10461, USA

2 Johns Hopkins Asthma and Allergy Center, Baltimore, MD, USA reported as severe, nor as the most troublesome symptom affecting a patient.

An informal poll of the Directors of 17 subspecialist Cough Centers worldwide (six in the USA; five in the United Kingdom; one each in Canada, China, Germany, Italy, Japan and South Korea) yielded a consensus that chronic cough after COVID-19 was to date either a never-seen, rare or uncommon event at their specialty Cough Centers. Anecdotal experience consistently described that fatigue, dyspnea with exertion and chest tightness/discomfort were more commonly reported than cough, and when cough was described (often as a response to a prompt rather than as an unsolicited complaint), it was not severe nor particularly troublesome.

Indeed, initial published data reporting on respiratory symptoms in patients after SARS-CoV-2 infection describe a higher prevalence of symptoms other than cough. In a study from Italy evaluating 143 patients who had been hospitalized for COVID-19 and subsequently discharged, at a mean of 60.3 days after symptom onset, fatigue, dyspnea, joint pain and chest pain were reported more frequently than cough, which was described by approximately $16 \%$ of patients [8]. In a follow-up study of 119 patients with COVID-19 who had recovered from severe pneumonia in the United Kingdom (UK), troublesome chronic cough after 2 months was reported by only $7 \%$ of patients, whereas breathlessness was described by $32 \%$ of subjects as a significant complaint [9]. In another UK study, 110 patients who had been hospitalized with COVID-19 were prospectively evaluated in-person at a median (IQR) of 90 (80-97) days after symptom onset. Fatigue and breathlessness were each reported by $39 \%$ of the cohort as residual symptoms, whereas cough was reported by only $11.6 \%[10]$.

There are several viable hypotheses to account for the emergence of coughing during active SARS-CoV-2 infection. As with most respiratory viruses a primary site of entrance for COVID-19 is the respiratory epithelium. The vagal sensory nerves that play essential roles in regulating cough terminate in the epithelium and subepithelial mucosa of the human airways [11]. Airway epithelial cells synthesize 
and release many autacoids, growth factors and cytokines that can engage receptors and ion channels on the peripheral terminals of airway sensory nerves to evoke action potential discharge and coughing or modulate excitability of these nerves to subsequent irritation [12-14]. SARS-CoV-2 uses the cell surface protein angiotensin-converting enzyme type 2 (ACE2) for docking and cellular entry on mucosal surfaces [15]. ACE2 is richly expressed in upper and lower airway epithelial cells and among its many functions, this enzyme regulates mucosal concentrations of the pro-inflammatory peptide bradykinin [16]. It has been speculated and at least partially confirmed in a small clinical study that unchecked bradykinin formation may account for some of the serious systemic consequences of SARS-CoV-2 infection [17-20]. Bradykinin also evokes coughing [21]. The emergence of cough during infection could thus be the result of an epithelial cell insult resulting in the release of pro-inflammatory autacoids, neurotrophins, cytokines and alarmins (e.g. ATP) that may evoke coughing or sensitize the airways to mucosal irritation.

If early indications suggesting an absence of prolonged coughing are confirmed as the pandemic progresses and more patients enter the post-infectious stage, we can speculate about why cough would be absent despite persistent fatigue and dyspnea, the latter suggesting sustained activation of vagal sensory nerves. It is noteworthy, for example, that unlike many respiratory viral infections, SARS-CoV-2 infection often results in pneumonia and acute lung injury involving the most peripheral conducting airways and alveoli. The sensory innervation and associated reflexes of the large conducting airways (larynx, trachea, mainstem bronchi) are very different from those of the more peripheral airways and alveoli eventually impacted by SARS-CoV-2 [22, 23]. In animals, subtypes of $\mathrm{C}$-fibers differentially innervate these airway and lung regions and may have opposing effects on cough. Not surprisingly, the C-fibers associated with large conducting airways have been implicated in transducing cough and reflex-mediated bronchospasm and mucus secretion. By contrast, the $\mathrm{C}$-fibers preferentially innervating the distal airways and alveoli regulate respiratory drive and likely induce the sensation of dyspnea upon activation [24]. There is evidence from studies performed in multiple species including humans that activation of the "pulmonary" C-fibers associated with the distal airways actively inhibits coughing upon activation [24-27].

In summary, clinical experience in the early aftermath of the first wave of the COVID-19 pandemic indicates that postviral chronic cough is neither a frequent nor debilitating residual effect. The symptoms of fatigue, dyspnea and chest tightness/discomfort have been reported with significantly greater frequency than cough. Further published data on this topic will be awaited with interest.

\section{References}

1. Morice AH, Millqvist E, Bieksiene K et al (2020) ERS guidelines on the diagnosis and treatment of chronic cough in adults and children. Eur Respir J 55:1901136

2. Dicpinigaitis PV (2012) Thoughts on one thousand chronic cough patients. Lung 190:593-596

3. Footitt J, Johnston SL (2009) Cough and viruses in airways disease: mechanisms. Pulm Pharmacol Ther 22:108-113

4. Zaccone EJ, Undem BJ (2016) Airway vagal neuroplasticity associated with respiratory viral infections. Lung 194:25-29

5. O'Connell F, Thomas VE, Studham JM et al (1996) Capsaicin cough sensitivity increases during upper respiratory infection. Respir Med 90:279-286

6. Dicpinigaitis PV, Bhat R, Rhoton WA et al (2011) Effect of viral upper respiratory tract infection on the urge-to-cough sensation. Respir Med 105:615-618

7. Dicpinigaitis PV, Tibb AS, Ramsey DL et al (2014) Stability of cough reflex sensitivity during viral upper respiratory tract infection (common cold). Pulm Pharmacol Ther 28:154-157

8. Carfi A, Bernabei R, Landi F et al (2020) Persistent symptoms in patients after acute COVID19. JAMA 324:603-605

9. D'Cruz RF, Waller MD, Perrin F et al (2020) Chest radiography is a poor predictor of respiratory symptoms and functional impairment in survivors of severe COVID-19 pneumonia. ERJ Open Res, in press. https://doi.org/10.1183/23120541.00655-2020

10. Arnold DT, Hamilton FW, Milne A et al (2020) Patient outcomes after hospitalisation with COVID-19 and implications for follow-up; results from a prospective UK cohort. medRxiv 2020.08.12.20173526. https://doi.org/10.1101/2020.08.12.20173 526

11. West PW, Canning BJ, Merlo-Pich E et al (2015) Morphologic characterization of nerves in whole-mount airway biopsies. Am J Respir Crit Care Med 192(1):30-39

12. Zaccone EJ, Lieu T, Muroi Y et al (2016) Parainfluenza 3-induced cough hypersensitivity in the guinea pig airways. PLoS One 11(5): $\mathrm{e} 0155526$

13. Deng Z, Zhou W, Sun J et al (2018) IFN- $\gamma$ enhances the cough reflex sensitivity via calcium influx in vagal sensory neurons. Am J Respir Crit Care Med 198(7):868-879

14. Patil MJ, Ru F, Sun H et al (2020) Acute activation of bronchopulmonary vagal nociceptors by type I interferons. J Physiol. https:// doi.org/10.1113/JP280276

15. Scialo F, Daniele A, Amato F et al (2020) ACE2: the major cell entry receptor for SARS-CoV-2. Lung. https://doi.org/10.1007/ s00408-020-00408-4

16. Colarusso C, Terlizzi M, Pinto A et al (2020) A lesson from a saboteur: high-MW kininogen impact in coronavirus-induced disease 2019. Br J Pharmacol 177(21):4866-4872

17. Garvin MR, Alvarez C, Miller JI et al (2020) A mechanistic model and therapeutic interventions for COVID-19 involving a RASmediated bradykinin storm. Elife 9:e59177

18. Roche JA, Roche R (2020) A hypothesized role for dysregulated bradykinin signaling in COVID-19 respiratory complications. FASEB J 34(6):7265-7269

19. van de Veerdonk FL, Kouijzer IJE, de Nooijer AH et al (2020) Outcomes associated with use of a kinin B2 receptor antagonist among patients with COVID-19. JAMA Netw Open 3(8):e2017708

20. van de Veerdonk FL, Netea MG, van Deuren M et al (2020) Kallikrein-kinin blockade in patients with COVID-19 to prevent acute respiratory distress syndrome. Elife 9:e57555

21. Hewitt MM, Adams G Jr, Mazzone SB et al (2016) Pharmacology of bradykinin-evoked coughing in guinea pigs. J Pharmacol Exp Ther 357(3):620-628 
22. Undem BJ, Chuaychoo B, Lee MG et al (2004) Subtypes of vagal afferent C-fibres in guinea-pig lungs. J Physiol 556(Pt 3):905-917

23. Chou YL, Scarupa MD, Mori N et al (2008) Differential effects of airway afferent nerve subtypes on cough and respiration in anesthetized guinea pigs. Am J Physiol Regul Integr Comp Physiol 295(5):R1572-R1584

24. Chou YL, Mori N, Canning BJ (2018) Opposing effects of bronchopulmonary C-fiber subtypes on cough in guinea pigs. Am J Physiol Regul Integr Comp Physiol 314(3):R489-R498

25. Tatar M, Webber SE, Widdicombe JG (1988) Lung C-fibre receptor activation and defensive reflexes in anaesthetized cats. J Physiol 402:411-420
26. Stone RA, Worsdell YM, Fuller RW et al (1993) Effects of 5-hydroxytryptamine and 5-hydroxytryptophan infusion on the human cough reflex. J Appl Physiol 74(1):396-401

27. Tatar M, Sant'Ambrogio G, Sant'Ambrogio FB (1994) Laryngeal and tracheobronchial cough in anesthetized dogs. J Appl Physiol 76(6):2672-2679

Publisher's note Springer Nature remains neutral with regard to jurisdictional claims in published maps and institutional affiliations. 